\title{
TEORIA FONOLÓGICA E VARIAÇÃO LINGUÍSTICA APLICADAS A LIBRAS
}

\author{
Luiz Antonio Zancanaro Junior* \\ Dr $^{\mathrm{a}}$ Teresinha de Moraes Brenner"*
}

\begin{abstract}
Resumo: Este trabalho desenvolve uma revisão bibliográfica baseada em dois eixos: princípios estruturalistas e variação linguística, com aplicação na língua de sinais. Na teoria saussuriana, destacam-se quatro pares de conceitos centrais, que são: "sincronia e diacronia", "língua e fala", "significante e significado" e "paradigma e sintagma". Essas dicotomias podem ser relacionadas com os estudos linguísticos da língua de sinais. O objetivo consiste em analisar três categorias da fonologia dessa língua: configuração de mão, locação e movimento, buscando, assim, investigar os traços distintivos dentro dessas categorias. Observa, pois, a ocorrência de mudanças das unidades mínimas que podem gerar itens lexicais com mesmos significados, e a relação com o termo de variante fonológico ou alofone.
\end{abstract}

Palavras-chave: Libras. Estudos estruturalistas. Variação Linguistica.

\begin{abstract}
This paper develops a literature review based on two axes: structuralist principles and linguistic variation, applied in sign language. In Saussurean theory, stand out four pairs of central concepts, they are: "synchrony and diachrony", "language and speech", "signifier and signified" and "paradigm and syntagm." These dichotomies can be related to the linguistic studies of sign language. The objective is to analyze three categories of the phonology of sign language: handshape, location and movement, seeking thus to investigate the distinctive features of the categories. Therefore, notice the occurrence of changes in minimum units that can generate lexical items with the same meanings, and the relationship with the term phonological variant or allophone.
\end{abstract}

Keywords: Libras. Structuralist studies. linguistic variation.

\section{Introdução}

As Línguas de Sinais foram sistematizadas há menos de um século . O processo se fez pela comparação com outras línguas já estudadas e reconhecidas secularmente. Isso ocorreu por que, nas línguas de sinais, ainda não se registrava um padrão de descrição fonológica, morfológica e sintática. Em consequência, os pesquisadores, muitas vezes, utilizavam generalizações de outras línguas para denominar as ocorrências encontradas nas línguas de sinais. Outro aspecto importante é que, pela falta de uma padronização, os estudiosos atrelavam as pesquisas ao entendimento ou intuição dos falantes nativos, ou seja, não havia uma teoria sobre a língua. A busca de dados científicos relacionados à língua de sinais, com enfoque linguístico, até os dias atuais, se demarca como tarefa árdua. Existe uma grande dificuldade em selecionar documentos na área da Linguística, porque faltam muitas fontes sobre o assunto, principalmente quando se fala em processo mais específico como o de variação.

A comunidade surda brasileira conseguiu que o Poder Legislativo aprovasse a Lei $n^{\circ}$ 10.436, de 2002, que reconhece a Língua Brasileira de Sinais como meio legal de comunicação e expressão. Garante, também, aos alunos surdos, regularmente matriculados em escolas públicas ou privados, a presença do profissional intérprete para mediar a comunicação. Essa lei foi regulamentada pelo Decreto 5.626, de 2005.

\footnotetext{
" Graduado em Letras/LIBRAS pela Universidade Federal de Santa Catarina. Mestrando em Linguística Aplicada na UFSC. Endereço eletrônico: zancanaro@univali.br

Orientadora da disciplina de Fonologia no Programa de Pós-Graduação em Linguística da UFSC. Endereço eletrônico: teresinha.brenner@ufsc.br
} 
Segundo Felipe (2004), a Libras (Língua Brasileira de Sinais) caracteriza-se como língua natural da comunidade surda brasileira, estando, dessa forma, inserida nas culturas, bem como nas políticas linguísticas e sociais. A Língua de Sinais classifica-se como de modalidade visual-gestual, porque constitui um meio de comunicação produzido por configurações de mãos, movimento, locação, além da expressão facial e corporal, ou seja, as informações linguísticas são percebidas pela visão. Eis a diferença da Língua Portuguesa, que representa uma língua de modalidade oral-auditiva, por utilizar, os sons articulados como percebidos pela audição.

O presente trabalho pretende apresentar um método de análise de três categorias da fonologia da língua de sinais: configuração de mão, locação e movimento. Deste modo, busca-se analisar os traços distintivos dentro dessas categorias. Focalizam-se as formas dos sinais, comparando-se um dicionário de Língua de Sinais e a língua em uso, no contexto. Observa-se, pois, a ocorrência de mudanças das unidades mínimas que podem gerar itens lexicais com mesmos significados.

\section{Princípios estruturalistas com aplicação à Língua de Sinais}

Considera-se o suíço Ferdinand de Saussure, nascido em Genebra, em 26 de novembro de 1857, o pai da linguística moderna. Ele lecionou três cursos de Linguística Geral: exposição relativa às línguas indo-europeias, sua história e sua descrição, nos anos de 1906-1907, 1908-1909 e 1910-1911, na Universidade de Genebra, na Suíça. Alguns alunos seus anotavam as aulas, e logo após sua morte, em 1916, publicaram a famosa obra intitulada Curso de Linguística Geral, uma produção póstuma, contendo boa parte do pensamento do Mestre. Faleceu em 1913.

As buscas linguísticas modernas que analisam a obra de Saussure retomam o termo "dicotomia", por ele definido. O vocábulo expressa a divisão lógica de um conceito em dois, de modo que, nessa bipartição, um deles se mostra contrário ao outro. Na teoria saussuriana, destacam-se quatro pares de conceitos centrais. São eles: "sincronia e diacronia", "língua e fala", "significante e significado" e "paradigma e sintagma". Essa conceituação pode ser encaixada nos estudos linguísticos da língua de sinais. A articulação será aqui sustentada pelas seguintes referências bibliográficas: Texto-base da disciplina de Introdução aos Estudos Linguísticos (Curso de Letras/Libras da UFSC), Evani Viotti, Curso de Linguística Geral, de Ferdinand de Saussure, Introdução à fonética e à fonologia da Língua portuguesa, de Sidneya Gaspar de Oliveira e Teresinha de Moraes Brenner e Manual de Linguística, de Marcos Antonio Costa. Primeiramente, considerar-se-á a oposição entre "significante e significado".

\section{Significante e Significado}

A teoria saussuriana afirma que a língua se organiza como um sistema de signos, cuja unidade se centraliza no signo linguístico. Ele é formado por duas partes, como as duas faces de uma folha de papel: um significante e um significado. Essas duas entidades que o compõem possuem correspondência psíquica e se ligam por um vínculo de associação.

Os signos linguísticos se caracterizam como convencionais e se compõem pelo significante, também chamado de imagem acústica, que "não é o som material, coisa puramente física, mas a impressão psíquica desse som" (Saussure, 2006: 80), e pelo significado, também chamado de conceito. Ambas as partes se tornam inseparáveis e juntas formam o signo, semelhante a uma moeda, como na Fig. 1 abaixo, inspirada no autor genebrino: 


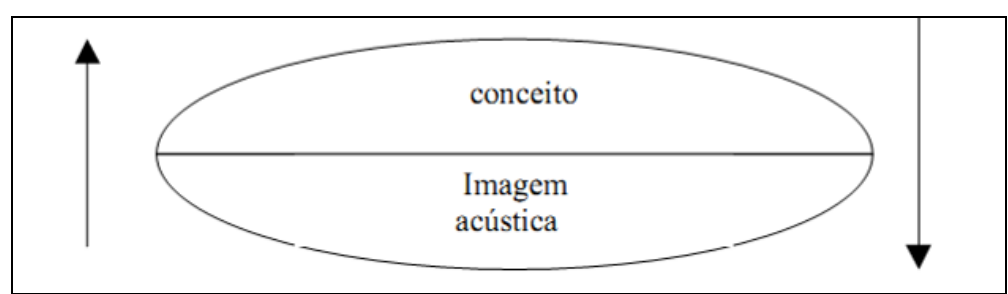

Figura 1 - Duas faces de uma moeda

Para exemplificar: quando um falante de língua portuguesa percebe, através do ouvido, a impressão psíquica transmitida pela imagem acústica ou significante $/ \mathrm{kaRo} /$, manifesta-se fonicamente o signo carro. Por outro lado, evoca psiquicamente a ideia de automóvel, que anda na estrada para algum lugar, corre, trafega sobre quatros rodas, entre outras. A Fig. 2 demonstra que o falante de língua portuguesa demarca o significante /KaRo/ (Carro) como ponto de referência para o conceito.

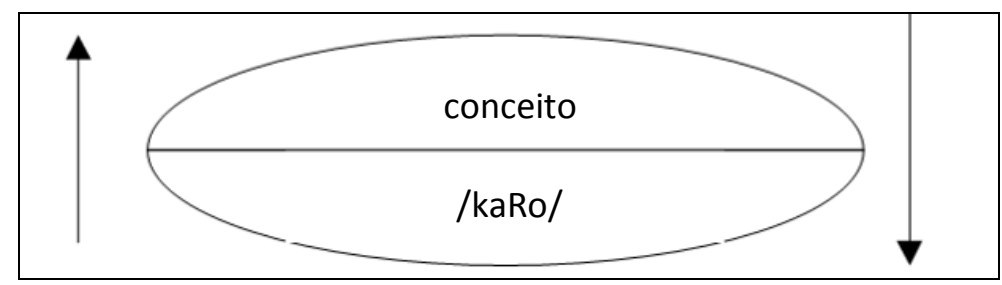

Figura 2- Duas faces de uma moeda

Em Libras, existe o signo linguístico da mesma forma que nas outras línguas. Conforme Taub (2001), quem primeiro descreveu a estrutura dos sinais foi Stokoe, em 1960, o pai da Línguística das Línguas de Sinais. No modelo de Stokoe, os sinais reúnem combinações simultâneas de organização dos elementos das línguas de sinais: a configuração da mão, a locação (lugar no corpo ou no espaço onde o sinal se produz) e o movimento. Posteriormente, novos teóricos, com novas pesquisas, acrescentaram os parâmetros de orientação (a direção que a palma da mão faz os "pontos"), bem como expressões faciais e corporais (denominadas sinais não-manuais).

O signo linguístico da língua de sinais dá origem ao significado, de caráter conceitual, e, por outro lado, cria o significante, imagem ótica (no caso de língua de sinais) ou mental (no caso de língua oral). Juntos, formam o signo linguístico. A Fig. 3 exibe a representação das duas faces de uma moeda (imagem mental de carro e do outro lado, imagem visual de sign write $^{1}$ ), com base na língua de sinais. Quando um sujeito recebe a imagem, ele transmite por meio da impressão ótica o significante de "carro", em seguida produz, com as mãos o gestual, incluindo os parâmetros: configuração de mão em "S", movimento (mãos em "S" movem em arcos alternados, para os lados e para cima, e para baixo) e locação (mãos em "S" não toca no corpo, fica no espaço neutro). Essas combinações podem, ainda, levar a entender que o carro anda na estrada. Para a criação do significante, é, pois, necessário que se tenha um sentido, um significado.

\footnotetext{
${ }^{1}$ O sistema de escrita para línguas de sinais denominado Sign Writing foi inventado em 1974 por Valerie Sutton, na Deaf Commitee (DAC), uma organização sem fins lucrativos sediada em La Jolla, Califórnia, USA. No início, era um sistema que a autora criou para anotar os movimentos da dança. A pesquisa desse sistema, Sign Writing (SW), no Brasil foi desenvolvida pela Doutora surda Marianne Stumpf, que defendeu a sua tese com esse tema. Agora esse sistema é conhecido no Brasil como ELS (Escrita em Língua de Sinais). Atualmente, na Graduação de Letras/Libras de algumas Universidades no Brasil, esse sistema aparece em disciplinas do currículo.
} 


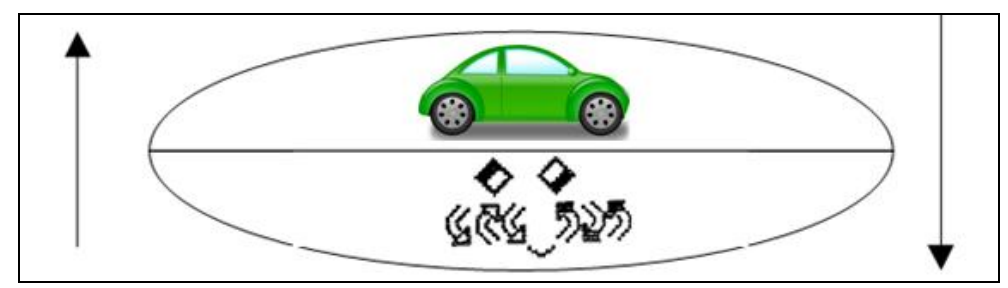

Figura 3- Duas faces de uma moeda

É importante abordar a questão da oposição entre arbitrariedade e iconicidade do signo linguístico, e explorar a corrente linguística atual. A noção de arbitrariedade está principalmente relacionada ao fato de que não existe uma relação motivada entre o som, $o$ significante, e o significado da palavra, o conceito. Essa relação não ocorre de forma natural: por exemplo, a moradia para um indivíduo também se denomina "casa", mas, em outras línguas, registram-se palavras com estruturas sonoras bem diferentes para designar o mesmo significado como house, em inglês, e maison, em francês.

Alguns estudiosos se opuseram a Saussure, quanto à arbitrariedade, argumentando que as onomatopeias teriam uma motivação metafísica, pois a noção de iconicidade do signo linguístico começa na afirmação de que as onomatopeias são ideais de uma motivação, o que possibilita a "imaginação estrutural de uma palavra", relacionando o natural entre os elementos e sentidos que eles expressam. Assim, palavras seriam estruturas sonoras que imitariam o som dos seres que elas designam. Por exemplo, os signos "cocorocó" (som do canto do galo), "tique-taque" (o barulho feito pelo relógio), entre outros, quando atualizados no ato da fala pelos falantes, levariam esses a tentar reproduzir as semelhanças existentes entre o real e o signo.

A defesa de Saussure a essa crítica se fundamenta em dois argumentos: primeiro, as onomatopeias se apresentam em número restrito nas línguas; e segundo, sua escolha se desenvolve de forma arbitrária, elas apenas se aproximam dos sons que ouvimos. A convencionalidade desses signos mostra o fato de que as onomatopeias se formam de um sistema fonético-fonológico das línguas. Então, isso significa que, em alguns casos, tentamos criar signos através da imitação dos sons e ruídos que ouvimos.

Quando se trata da língua de sinais, verificou-se, inicialmente, uma séria objeção a essa ideia de Saussure: nas diferentes línguas de sinais defendia-se iconicidade, representando a forma de objetos ou indivíduos. No entanto, Saussure não levou em consideração as línguas de sinais. Verificou-se que não só nas línguas de sinais, mas também nas línguas orais, muitos signos eram motivados: seus significantes procuravam transmitir os sons que os seres produziam (no caso das línguas orais), ou as formas que os objetos se apresentavam (no caso das línguas de sinais). Como decorrência, perdurou por algum tempo nas línguas de sinais um grau elevado de sinais icônicos (telefone, carro, casa) que traduziam a forma do objeto; no entanto, é importante ressaltar que essa não era a única característica da língua de sinais.

Atualmente os pesquisadores americanos que tratam do processo da mudança histórica da Língua de Sinais Americana (ASL) identificam que, no início, existiam, realmente, muitos sinais icônicos; todavia, com o passar do tempo eles foram diminuindo e, por consequência, os sinais arbitrários foram aumentando.

\section{Fala e Língua}

Os conceitos de língua (langue) e fala (parole) fundamentam a segunda dicotomia do linguista suíço. Para Saussure, a oposição entre os dois conceitos mostra que, de fato, a língua caracteriza-se como um sistema supra-individual no uso dos meios de comunicação na comunidade. Ela se define como sistemática, homogênea e abstrata. Já a fala se estrutura no uso individual do sistema, caracterizado como língua. Trata-se de um ato individual de 
vontade: ao falar, o falante faz as escolhas sobre o vocabulário que vai usar. Por isso, a fala particulariza-se como assistemática, heterogênea e física. Saussure afirma, no entanto, que, individualmente, não é possível mudar ou modificar a língua.

É relevante ilustrar a diferença entre língua e fala utilizando um exemplo do latim, que representa uma língua morta. Ninguém mais fala em latim, mas a língua ainda existe. Neste caso, os dois elementos (langue e parole) sustentam, ainda, a relação entre as unidades que constituem a dicotomia, gerando o valor linguístico e levando em consideração o falante virtual.

A segunda oposição aborda, pois, os conceitos de língua e fala. Saussure destaca que a língua representa a gramática do sistema. Para exemplificar, temos a Libras, utilizada na comunidade surda do Brasil. A Fig. 4 encontra-se no Dicionário enciclopédico ilustrado trilíngue da Língua de Sinais Brasileira (Libras). Este possui dois volumes e foi criado por Fernando César Capovilla e Walkiria Duarte Raphael, produzido e publicado pela Editora da Universidade de São Paulo, em 2001. Distribuiu-se o dicionário para todas as cidades brasileiras. Algumas comunidades surdas recebem-no para que o utilizem nas escolas e Universidades públicas e privadas, possibilitando o acesso e a aquisição de novos vocabulários.

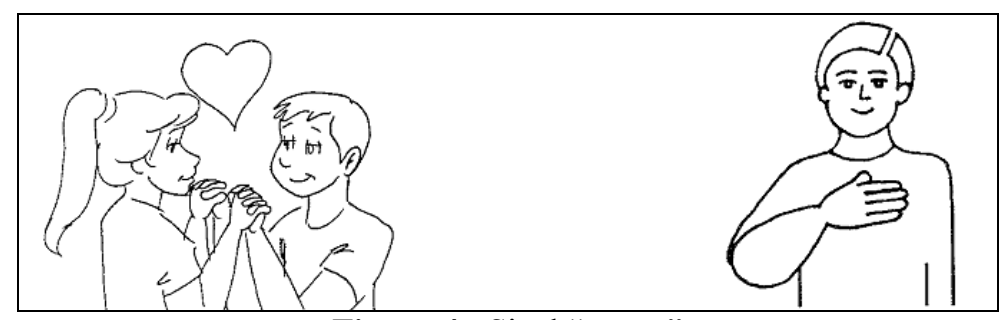

Figura 4 - Sinal "gostar"

A Fig. 4 apresenta o sinal "gostar" como uma fala individual de linguagem, como um sinal único, porém, as variações incontáveis que podem ocorrer no momento da fala não estão representadas. O indivíduo observa o sinal contido no dicionário, mas na fala cotidiana modifica de alguma forma algum dos parâmetros da Libras, quais sejam: movimento, locação e configuração. Como segue abaixo:

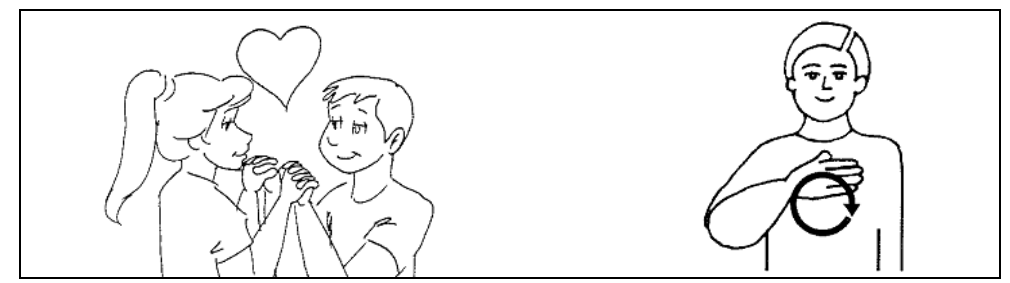

Figura 5 - Outros sinais de "gostar"

Na Fig. 5, apresentam-se três sinais distintos, utilizados por grupos de diferentes regiões. Os sinais mostram-se divergentes; sustenta-se, entretanto, o significado. Os fatores que interferem nessas produções podem ser de cunho social, cultural e psíquico, interagindo na linguagem.

\section{Diacronia e Sincronia}

Esta seção está relacionada ao método de investigação utilizado pela linguística em suas pesquisas: sincrônico e diacrônico. Trata-se de mais uma dicotomia proposta por Saussure e tem relação com o tipo de recorte cronológico que aplicaremos ao estudo da língua. A dicotomia apresenta-se construída sobre dois eixos: o eixo da linguística estática e o eixo da linguística evolutiva. O da linguística estática delimita-se como eixo sincrônico, 
método atual da linguística moderna, que se apresenta recentemente na história. Por outro lado, o eixo da linguística evolutiva é o diacrônico que se fundamenta nos estudos tradicionais das línguas realizados no século XIX. Tais estudos têm por objetivo a obtenção de dados. Esses são coletados em dois momentos históricos diferentes, para, assim, realizar uma análise comparativa de uma determinada língua.

Na Libras, é possível perceber, através da ilustração da Fig. 6, o método comparativo realizado durante um longo tempo. O trabalho consistiu na análise de dois dicionários em épocas distintas. A gravura da esquerda foi retirada do Iconographia dos Signaes dos SurdosMudos, pelo ex-aluno do INES (Instituto Nacional Educação de Surdos), Flausino José da Gama, em 1875. No lado direito, a gravura faz parte do Dicionário enciclopédico ilustrado trilíngue da Língua de Sinais Brasileira (Libras), em 2001.

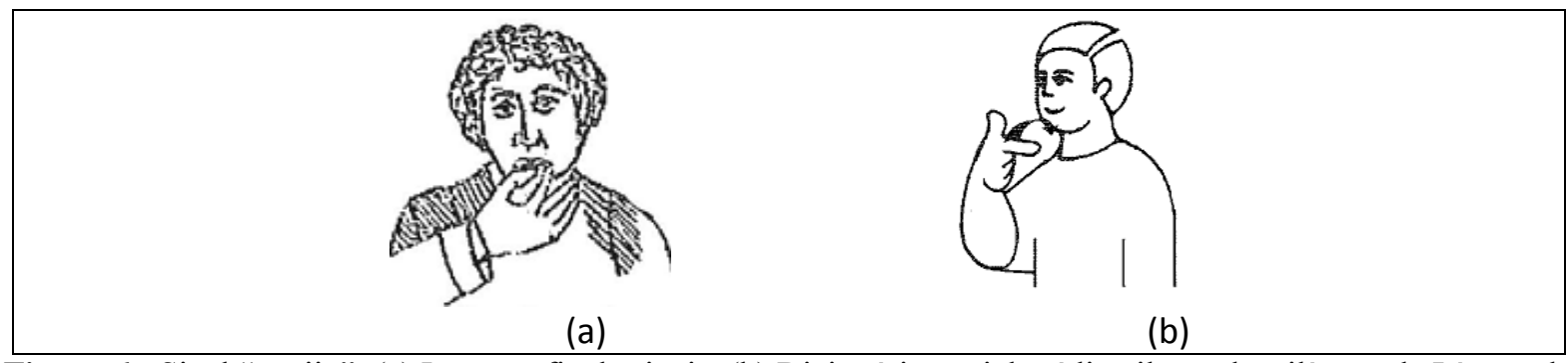

Figura 6 - Sinal "queijo": (a) Iconografia de sinais; (b) Dicionário enciclopédico ilustrado trilíngue da Língua de Sinais Brasileira

Como se pode observar nas imagens acima, houve uma mudança no sinal "queijo" usado em 1875 e 2001. Percebe-se que as mudanças lexicais dos sinais são bastante significativas, ou seja, atualmente usam-se poucos sinais idênticos aos de 1875. Deste modo, a língua passou por mudança ao longo do tempo, e isso se comprova de diversas formas.

\section{Sintagma e Paradigma}

Essa representa uma dicotomia de muito conteúdo teórico a ser entendida. Ela dá conta do fato de que que todos os elementos se definem pelas relações que estabelecem com outros elementos e com o próprio sistema linguístico. A relação de diferenças e oposições estabelecidas entre os elementos constituem o sistema separado em dois grupos. Cada grupo corresponde a uma forma de atividade mental e ambos são fundamentais para a língua.

O estudo desse grupo de relação trata da linearidade do significante. Nesse sentido, Saussure ressalta uma marca observada na língua oral: o significante das línguas é a estrutura acústica, que deve se desenvolver em uma sequência linear. Isso quer dizer que, para Saussure, não existe simultaneidade na língua. Esse é o caso do acento de tonicidade sobre uma sílaba, pois existe diferença significativa entre as sílabas tônicas e as átonas de uma mesma palavra. Em algumas línguas orais, como no português, o acento da palavra distingue significado, como se observa nos signos: "sábia", "sabia" e "sabiá". Assim, na questão relativa ao acento tônico, pode-se observar a linearidade da emissão acústica, já que as sílabas vão sendo faladas uma após a outra, e não simultaneamente. Além disso, cada palavra tem uma pronúncia distinta.

Já na língua de sinais, a simultaneidade constitui um fato, já que um signo é realizado com uma mão e outro com a outra, ou seja, ao mesmo tempo, as mãos estão realizando sinais lexicais, assim como a posição do tronco e da cabeça, a direção do olhar e as expressões faciais estão passando informações discursivas e gramaticais.

Deste modo, a dicotomia sintagma versus paradigma pode ser definida em dois eixos: o primeiro corresponde a uma linha horizontal e o segundo, a uma vertical. O eixo 
sintagmático, da linearidade, corresponde à sintaxe. Refere-se à ordem dos elementos e à combinação de palavras, que podem ser associadas, por exemplo: em uma expressão como "vou ao cinema". Restringe a mudança da ordem dos constituintes à semântica: a ordem dos constituintes não se torna aleatória, como "cinema ao vou", "ao cinema vou" ou "cinema vou ao". Fonologicamente, também há algumas restrições, como: depois do fonema $/ \mathrm{b} /$, pode ocorrer uma vogal- como em "bata", "bebe", "bicho", ou a consoante /r/ ou /1/, como em "brasa", "blusa". Então, não se podem acrescentar as demais consoantes, como /p/, /t/, /s/. Para exemplificar em Libras, veja a Fig. 7.

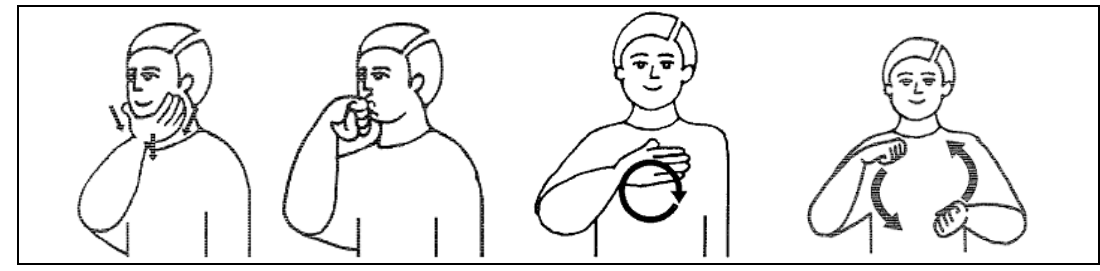

Figura 7- expressa a ordem; a tradução em português: "o pai gosta de carro"

Essa sintaxe de Libras mostra-se adequada, isto é, a ordem dos elementos gramaticais diz que o verbo liga sujeito ao objeto.

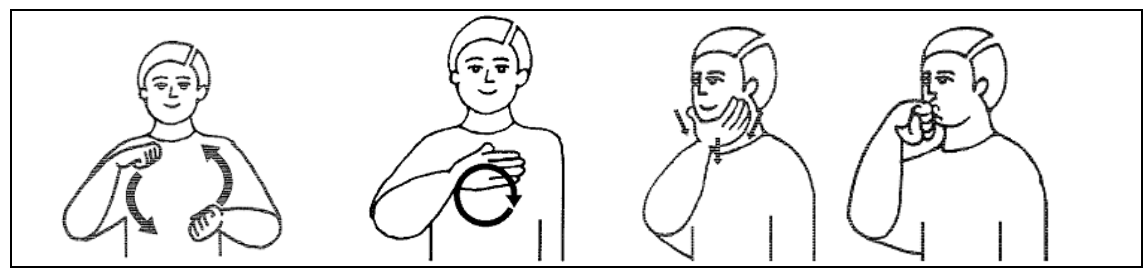

Figura 8- expressa a desordem. Tradução para o português: "o carro gosta de pai”

A estrutura acima está inadequada, pois é o objeto (anteposto) que se liga pelo verbo ao nome (sujeito, posposto). A frase anterior estava correta. A regra não é exclusiva ou imutável, pode variar de acordo com o contexto e a ligação pretendida em Libras.

O eixo paradigmático ou eixo vertical identifica-se como o das relações de substituição. Este tem relação com as unidades comutáveis, que se dão em ausência, em fonologia. O processo da comutação pode distinguir 7 vogais em português, na linha paradigmática. É necessário comutar segmentos em dado ponto da cadeira falada. Em: "fada", "fede", "fidi", "fodo" e fudu", por exemplo, obtivemos alterações nos significados das palavras porque mudamos as vogas $(/ \mathrm{a} /, / \varepsilon / \mathrm{e} / \mathrm{o} /)$, o que nos permite concluir que $/ \mathrm{a} /, / \varepsilon /$, /o/ são fonemas da língua portuguesa brasileira, representados pelas letras a, e, o, respectivamente. Por outro lado, quando usados os fonemas /i/ e /u/ não existe significado nas sequências sonoras correspondentes em língua portuguesa brasileira (Oliveira \& Brenner, 1988). Embora Saussure não tenha formulado um conceito preciso, ele mostra que "os fonemas são antes de tudo entidades opositivas, relativas e negativas". Assim, Saussure evidencia o valor diferencial dos fonemas, mas não sua verdadeira propriedade. Percebe o fonema no sistema, isto é, dentro das relações estabelecidas e da função que desempenha.

A combinação de palavras ou morfemas que podem se relacionar estabelece a associação sintagmática. Por exemplo: re-ler; o menin-o; fal-á-va-mos. É importante ressaltar que os sintagmas e os paradigmas seguem a regra da língua para que essa relação associativacombinativa ocorra.

Para exemplificar os dois eixos em Libras: "O pai compra um carro". Essa oração expressa um constituinte principal com núcleo verbal, podendo este ser substituído por outros verbos, como "vender", "ver", "quebrar", entre outros. Forma-se, assim, a relação 
substitutiva, que se liga à sintagmática, e se estabelece a organização de um sistema linguístico.

\section{Variação Linguística}

Este tópico aborda dois temas: fonema versus alofone e a unidade mínima de diferença na Libras, analisando, assim, categorias que podem ser comparadas na língua portuguesa oral e na língua de sinais no Brasil.

\subsection{Fonema x Alofone}

Esta secção tem como foco de interesse a utilização da língua por diferentes pessoas, em lugares diversos. O modo de falar de uma pessoa varia conforme a região geográfica na qual está inserida; o Brasil possui 26 estados, distribuídos em cinco regiões e cada uma delas apresenta um sistema específico de fala. Esses dialetos se tornam facilmente identificados pelos falantes, ou seja, distingue-se sem dificuldades a fala de um gaúcho, de um paulista, ou outros. Da mesma maneira, o estrangeiro que aprende o português também guarda características em seu idioleto que são percebidas pelos brasileiros.

No que diz respeito à variação, não se julga e nem se compara a forma de variante do uso de uma língua, afirmando que é mais ou menos perfeita, já que cada grupo de falantes expressa variantes sociais, ditas variantes de prestígio ou variantes estigmatizadas, conforme se observa no texto de Silva (1999: 12):

Falantes de qualquer língua prestigiam ou marginalizam certas variantes regionais (ou pelo menos não as discriminam), a partir da maneira pela qual as sequências sonoras são pronunciadas. Assim, determinamos variantes de prestígio e variantes estigmatizadas. Algumas variantes podem ser consideradas neutras do ponto de vista de prestígio. Temos em qualquer língua as chamadas variantes padrão e variantes não-padrão. Os princípios que regulam as propriedades das variantes padrão e não-padrão geralmente extrapolam critérios puramente linguísticos. Na maioria das vezes o que se determina como sendo uma variante padrão relaciona-se à classe social de prestígio e a um grau relativamente alto de educação formal dos falantes. Variantes não-padrão geralmente desviam-se destes parâmetros.

A mesma autora ressalta que nem sempre existe ligação entre as características das variantes padrão e não-padrão. Isso acontece, por exemplo, em Belo Horizonte (MG), a terminação -ndo, das estruturas de gerúndio, pronuncia-se como -no: "comeno", "fazeno", "quereno", "vendeno" etc. No entanto, percebe-se que esta redução de -ndo para -no ocorre somente no gerúndio. A forma verbal "(eu) vendo" não permite reduzir -ndo para -no, como não se registra uma sentença semelhante a "Eu veno banana".

A redução de -ndo para -no nas formas de gerúndio em Belo Horizonte (e em outras regiões do País) não segue a regra padrão; contudo, representa um fenômeno difundido entre os falantes, o que o integrou na variante padrão na capital de Minas Gerais.

É muito importante entender a variante não-padrão da teoria de Silva (1999). Ela exemplifica com as formas verbais e as pronominais utilizando a primeira pessoa do plural com duas sentenças distintas: "a gente gosta" e "nós gostamos". Ambas as estruturas são aceitas dentro da variante padrão em vários dialetos. O que caracteriza a variante não-padrão é a troca na combinação de pessoa com a forma verbal: "nós gosta" e "a gente gostamos". 
Conforme Beline (2011), a variação lexical se identifica como um modo como uma língua pode variar, pois dois vocábulos diferentes podem ter o mesmo referente no mundo, por exemplo, aipim e macaxeira. Já o estilo de se expressar do falante, mais formal ou mais informal, denomina-se variação diafásica. Atentando-se aos sons, pode-se identificar uma clara diferença entre falantes cariocas e paulistanos, pois o modo que eles pronunciam o/ $/ \mathrm{r}$ é distinto, no final de sílaba: paulistanos pronunciam tal -r como uma vibrante simples - um "flap" - e os cariocas aspiram o /r/. A pronúncia diversificada conforme o lugar caracteriza uma variação diatópica. Trata-se do mesmo vocábulo, com o mesmo significado, mas com pronúncia diferente.

Em português, dois sons - /s/ e / / / - podem opor-se fonologicamente quando expressam dois signos: "soco" /'soku/ e "choco"/'Sokv/. Eles são dois fonemas do português, sendo que ambos introduzem conceitos distintos. No entanto, a forma de tosco, quando pronunciada por falantes paulistanos e florianopolitanos, produz a fala: ['tosku] e ['tofku], respectivamente, apresentado significado igual. Nesta perspectiva, percebe-se uma mesma base fonêmica para [s] e [S] que apenas altera o significante e não produz a mudança de significado. Isso é considerado variante fonológica ou alofone; fato que não se observa diante das formas como "soco" e "choco", que se iniciam por dois fonemas introduzindo conceitos distintos. Geralmente, usa-se um alofone para representar o fonema (Seara, 2008).

Por outro lado, conforme se lê em Câmara Júnior (2008), pode-se dizer que, em termos diacrônicos, os alofones ou variantes livres são os intervalos de tempo para que se realize a mudança da regra fonológica. Na segunda articulação, a diferença entre o fonema e o alofone está na forma da língua. No português, por exemplo, o $/ \mathrm{r} /$ pode ser chamado de forte ou múltiplo (podendo ser vibrado, prolongado pela ponta da língua junto aos dentes superiores) ou ainda, velar (uma vibração da língua junto ao véu palatino), ou uvular (uma vibração da úvula, na parte extrema do véu palatino), ou fricativo (uma fricção da faringe). Opõe-se a um fonema / $/$ / chamado brando, isto é, resultante de um único golpe vibratório da ponta da língua junto aos dentes superiores. Essa oposição permite distinguir palavras como: erra/era, ferro/fero, carro/caro, e assim por diante.

Silva (1999: 135) destaca, ainda, o conceito básico de variação, afirmando que alofone é "unidade que se relaciona à manifestação fonética de um fonema. Alofones de um mesmo fonema ocorrem em contextos exclusivos. Método de identificação: distribuição complementar".

A noção de alofonia descreve aspectos relevantes da fonética e da fonologia. Pretende, ainda, fazer a representação das características dialetais de um falante de acordo com sua região e modelo sociocultural.

Segundo Silva (1999), alguns dados de alofonia em português registram os fonemas, expressando os detalhes. Aqui se optou por trabalhar as variantes fricativas de /R/, focalizado como $[\mathrm{x}, \mathrm{\gamma}, \mathrm{h}, \mathrm{h}]$, usando a posição final de sílaba, a qual concilia em vozeamento com a consoante seguinte. /R/ ocorre sempre em posição final ou inicial da sílaba ou no meio de palavra.

Os segmentos [x, y, h, h], em final de sílaba, relacionam-se ao /R/ forte, representado fonemicamente pelo /R/ . Registram-se, igualmente, em posição intervocálica, que opõe $o / R$ / forte e o / / fraco. $O$ fonema / $/$ fraco expressa-se em português, como o tepe intervocálico inicial de sílaba [r]. Assinala-se, por exemplo, em "caro", ou ainda, com a consoante precedente, na mesma sílaba, como em "prata". $\mathrm{O} / \mathrm{R} /$ forte ocorre em posição intervocálica, como em "carro", ou no início da palavra, como em "rua", ou no início da sílaba precedida por consoante, como em "Israel". 
Destaca-se, a seguir, a distribuição fonêmica da vibrante conforme o quadro de Silva (1999: 143) modificado pelo autor deste:

\begin{tabular}{|c|c|c|c|c|c|c|}
\hline & Ambiente & Exemplo & $\begin{array}{c}\text { Belo } \\
\text { Horizonte } \\
\end{array}$ & $\begin{array}{l}\text { Rio de } \\
\text { Janeiro }\end{array}$ & Caipira & Portugal \\
\hline \multirow{2}{*}{$\begin{array}{l}\frac{\mathscr{a}}{\theta} \\
\stackrel{-}{=}\end{array}$} & Intervocálica & Caro & $/ \mathrm{f} /[\mathrm{r}]$ & $/ \mathrm{c} /[\mathrm{c}]$ & $/ \mathrm{f} /[\mathrm{r}]$ & $/ \mathrm{/} /[\mathrm{r}]$ \\
\hline & $\begin{array}{l}\text { Seguindo } \mathrm{C} \text { na mesma } \\
\text { sílaba }\end{array}$ & Prato & $/ \mathrm{f} /[\mathrm{r}]$ & $/ \mathrm{f} /[\mathrm{r}]$ & $/ \mathrm{r} /[\mathrm{r}]$ & $/ \mathrm{f} /[\mathrm{r}]$ \\
\hline \multirow{3}{*}{ 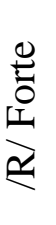 } & Intervocálica & Carro & $/ \mathrm{R} /[\mathrm{h}]$ & $/ \mathrm{R} /[\mathrm{x}]$ & $/ \mathrm{R} /[\check{\mathrm{r}}]$ & $/ \mathrm{R} /[\check{\mathrm{r}}]$ \\
\hline & Início de palavra & Rua & $/ \mathrm{R} /[\mathrm{h}]$ & $/ \mathrm{R} /[\mathrm{x}]$ & $/ \mathrm{R} /[\check{\mathrm{r}}]$ & $/ \mathrm{R} /[\check{\mathrm{r}}]$ \\
\hline & Seguindo $\mathrm{C}$ em outra sílaba & Israel & $/ \mathrm{R} /[\mathrm{h}]$ & $/ \mathrm{R} /[\mathrm{x}]$ & $/ \mathrm{R} /[\check{\mathrm{r}}]$ & $/ \mathrm{R} /[\check{\mathrm{r}}]$ \\
\hline \multirow{3}{*}{ 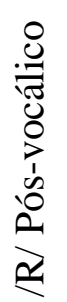 } & $\begin{array}{l}\text { Final de sílaba antes de } \mathrm{C} \\
\text { voz }\end{array}$ & Corda & $/ \mathrm{R} /[\mathrm{h}]$ & $/ \mathrm{R} /[\mathrm{x}]$ & $/ \mathrm{R} /[\mathrm{I}]$ & $/ \mathrm{R} /[\mathrm{r}]$ \\
\hline & $\begin{array}{l}\text { Final de sílaba antes de } \mathrm{C} \\
\text { desvoz }\end{array}$ & Torto & $/ \mathrm{R} /[\mathrm{h}]$ & $/ \mathrm{R} /[\mathrm{x}]$ & $/ \mathrm{R} /[\mathrm{I}]$ & $/ \mathrm{R} /[\mathrm{r}]$ \\
\hline & Final de palavra & Mar & $/ \mathrm{R} /[\mathrm{h}]$ & $/ \mathrm{R} /[\mathrm{x}]$ & $/ \mathrm{R} /[\mathrm{I}]$ & $/ \mathrm{R} /[\mathrm{r}]$ \\
\hline
\end{tabular}

Tabela 1- Alofonia de /R/ e de / $/$

Observa-se que existem dois fonemas $/ \mathrm{r} / \mathrm{e} / \mathrm{R} /$, que quando expressos em todos os dialetos do português, apresentam distinção.

Desse modo, o conceito de fonema tem como base a criação de variantes formadas pelo conjunto de fones que são foneticamente distintos, embora membros da mesma unidade fônica abstrata. Portanto, os fones são a realização do fonema e os alofones são as variantes fônicas de um fonema.

No entanto, os foneticistas percebem que se torna impossível fazer um inventário com todas as variações de um fonema, bem como com as variadas posições articulatórias, as quais não são imutáveis e identificam determinado som de uma língua cada vez que ele é ouvido. Quando os falantes articulam o mesmo fonema de forma divergente, ou um mesmo falante muda a articulação, ocorre uma nova variante para, assim, fixar registro, ambiente fonético e estilo de fala.

\subsection{A unidade mínima de diferença na Libras}

Acredita-se que, na Libras, existem alofones, visto que as comunidades surdas são isoladas; no entanto, se comunicam, facilmente, por meio digital (webcam, chat, internet) ou, ainda, se encontram em eventos (congresso, associações etc.), e esses fatores podem afetar a variante-padrão de Libras. A Fig. 9, abaixo, mostra que duas formas de sinais compostos como "pai" e "mãe" exemplificam o padrão nacional. Utilizam-se, ainda, variáveis de alguns estados do Brasil. Assim, no estado do Rio Grande do sul, produz-se uma forma de sinal simples, enquanto no Rio de Janeiro, sinalizam-se duas formas distintas, sendo que uma utiliza a soletração e outra, um sinal composto. Essas variações se constatam com regularidade no curso de Graduação de Letras-Libras da Universidade Federal de Santa Catarina. Nessa Instituição, alunos de diversos estados brasileiros se encontram e usam sinais 
diferentes para "pai" e "mãe". O quadro abaixo destaca as características de sinais de "pai" e "mãe":

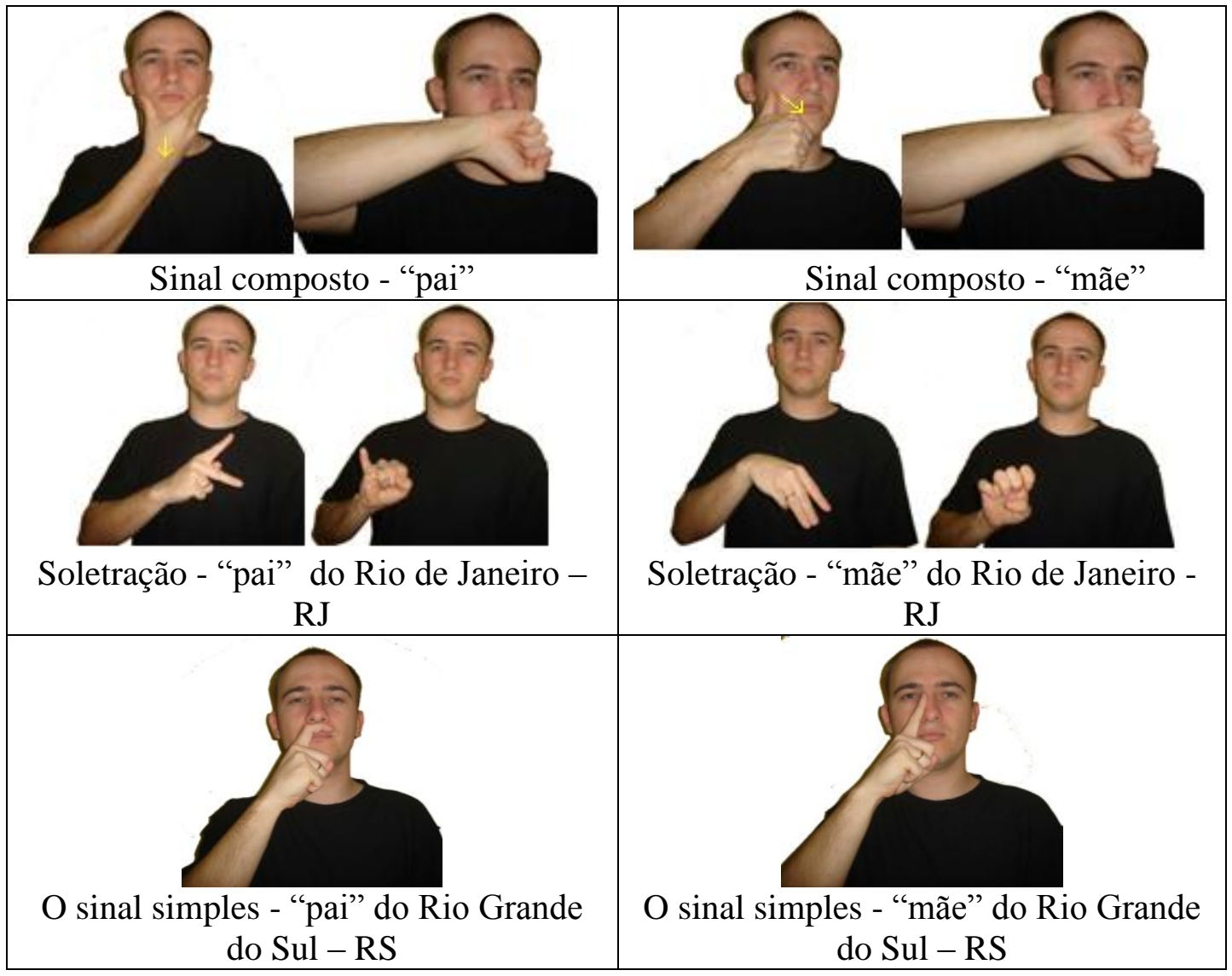

Figura 9- Variação dos sinais "pai" e "mãe" em diferentes Estados brasileiros

Neste contexto, pode ser estendido o princípio de variação ou alofonia usado no nível fonológico, para a Libras, pois cada estado produz de forma diferente os sinais. Seguem os exemplos da Libras nas três categorias: configuração, movimento e locação.

Nas línguas orais, um som isolado não expressa significado algum. Do mesmo modo, ocorre na Língua de Sinais, pois uma unidade mínima isolada não tem significado; no entanto, quando se liga a outras unidades mínimas, forma o morfema, agora com significado.

Os parâmetros das categorias definem regras de associação para expressar um significado, ou seja, uma configuração da mão se combina com a locação de mão, bem como com o movimento. A língua de Sinais não usa sons, mas ninguém pode negar que tenha uma organização nos sinais usados, regidos por regras combinatórias. Tanto os sinais quanto os sons são organizados e regulados por um sistema abstrato, que tem regras particulares, gerais e universais. Toda a língua de sinais de modalidade visual-espacial tem como referência principal comunicativa as mãos e os olhos. Assim sendo, segue princípio fonológico e faz parte do sistema linguístico. A língua portuguesa, no Brasil, possui, em seu alfabeto fonético, 26 símbolos representativos de fonemas; já a Libras possui 61 configurações de mão que, por sua vez, não representam os fonemas do português, mas, sim, são usadas a fim de dar valor linguístico contrastivo.

A Fig. 10 (abaixo) mostra configurações de mão utilizadas no Brasil, que serão usadas adiante no trabalho - imagem retirada da publicação de Pimenta, 2012: 


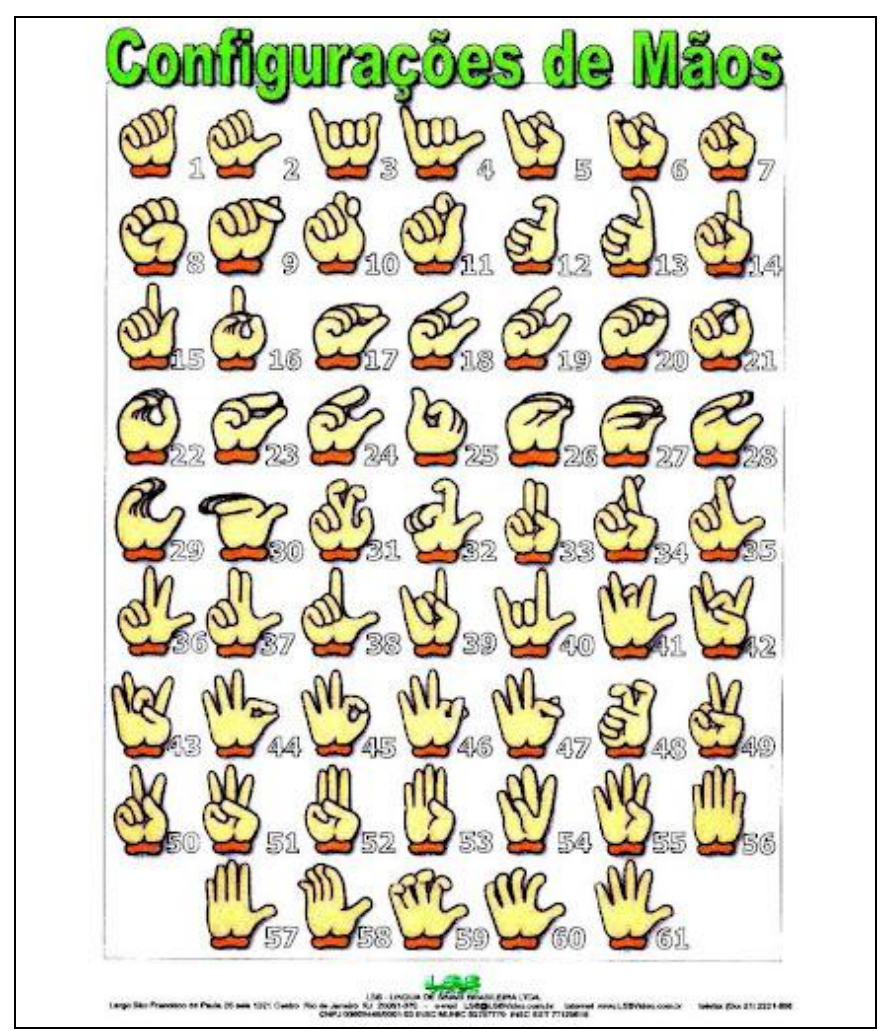

Figura 10- Configuração da mão

Faz-se, aqui, necessário apresentar o método de variação na Linguística de Libras, levando-se em conta as formas de sinais, observando os seus parâmetros, os quais apresentam três categorias fonológicas: configuração de mão, locação e movimento que possuem os traços distintos. Esses três parâmetros afetam as unidades mudadas, que permanecem com o mesmo significado.

Por meio de um levantamento feito no Dicionário Enciclopédico Ilustrado Trilíngue (Capovilla, 2001), percebeu-se que as formas de sinais expressam os parâmetros distintos para descrever com detalhes o que ocorre com a mão. Analisando, através da comparação entre o dicionário de Língua de Sinais e a língua em uso, nota-se que o primeiro possui gravuras que são fáceis de visualizar e com possibilidade de impressão. Já o segundo, por ser digital, está em formato de vídeo, o que torna mais difícil a visualização, fazendo-se, pois, necessárias algumas adaptações nas imagens.

Seguem abaixo exemplos de quadros com as duas formas de alguns sinais, onde se comparam unidades distintivas, situando-se à esquerda o dicionário e, à direita, imagens adaptadas. Torna-se importante fazer a relação das imagens a seguir com a Fig. 10, a fim de se compreender a configuração de mão utilizada.

a) A configuração de mão

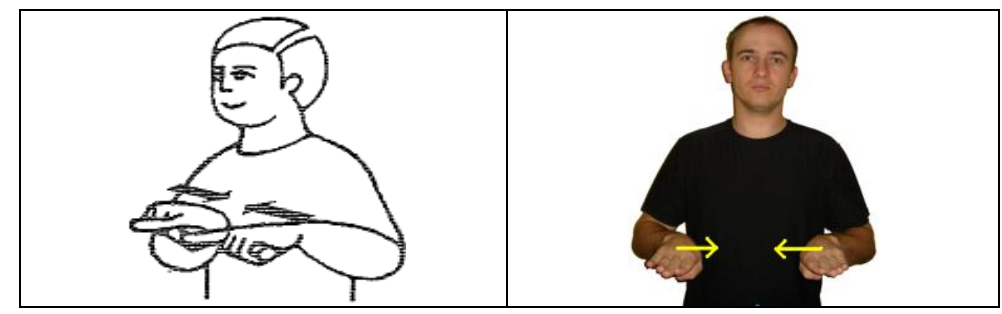

Figura 11- TRABALHAR: (a) Dicionário; (b) Língua em uso 
A Fig. 11 exibe: (a) configuração de mão 14, indicador para frente, lado a lado, aproximação das mãos, batendo a lateral dos indicadores, duas vezes; (b) afetar a mão em 53. Ambas têm combinação de locação e movimento da mão.

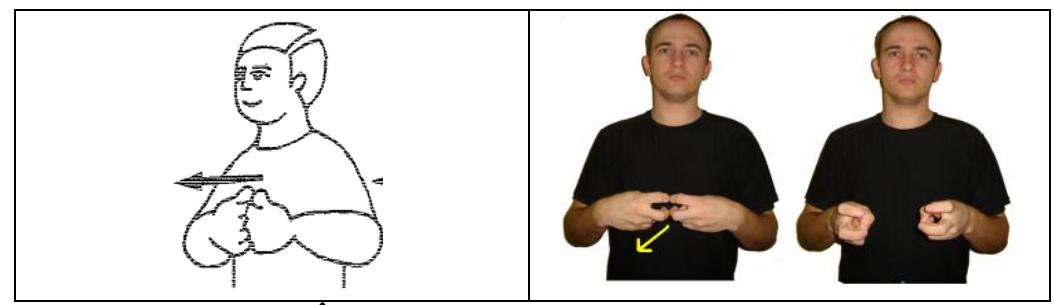

Figura 12 - ÔNIBUS: (a) Dicionário; (b) Língua em uso

A Fig. 12 exibe: (a) configuração de mão 1, segue na horizontal, palmas para dentro, tocando-se pelos nós dos dedos, move as mãos para frente; (b) configuração de mão 48. Ambas têm os mesmos parâmetros, exceto a configuração.

\section{b) Locação de mão}

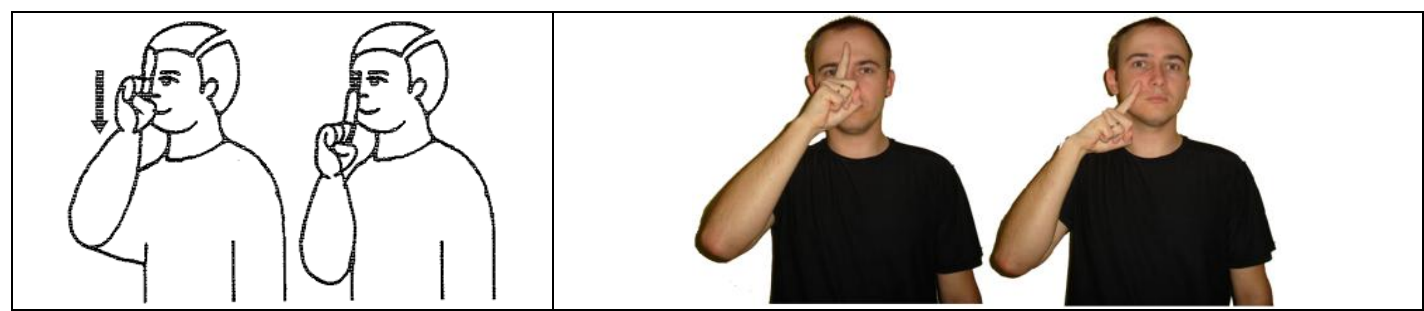

Figura 13 - AMARELO: (a) Dicionário; (b) autor deste trabalho

A Fig. 13 mostra: (a) configuração de mão 14, dedo do indicador tocando a testa para baixo, descendo a mão até o nariz; (b) a configuração de mão e movimentos são os mesmos, o que muda é a locação; enquanto uma imagem descreve o dedo indicador tocando a testa para baixo, a outra descreve o dedo sendo desviado do nariz.

c) Movimento de mão

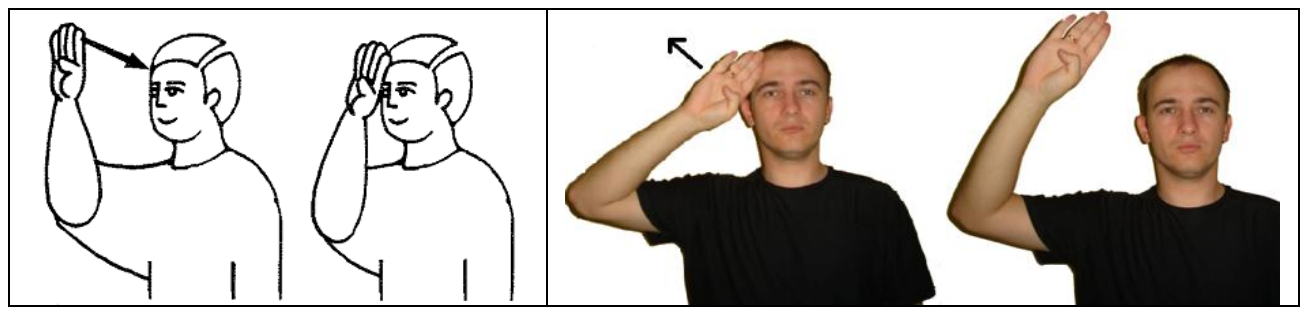

Figura 14 - SOLDADO: (a) Dicionário; (b) Língua em uso

Já na Fig. 14 nota-se que: (a) configuração de mão em 53, move a testa para tocar o indicador na testa; (b) constate no movimento que a mão solta da testa e segue para frente.

A ideia de que a mudança afeta o léxico e que pode se difundir, gradualmente, tem sido uma constante nas mudanças sonoras (Labov,1994) e nos traços formais do léxico substantivo. Todavia, a Língua de Sinais não utiliza o som das palavras. Explora, no entanto, as mãos no processo de mudança fonológica. 


\section{Considerais Finais}

Este trabalho procurou trazer, para a comunidade linguística, uma contribuição para a descrição da Libras. Apresentou três categorias da Língua de Sinais, visando analisar os traços distintivos: configuração, locação e movimento de mão. Tentou comparar um dicionário de Língua de Sinais com a língua em uso, de modo a observar a ocorrência de mudanças das unidades mínimas que podem vir a gerar itens lexicais com os mesmos significados.

Nessa perspectiva, pode-se dizer que essas mudanças são relevantes, pois é por meio delas que se pode verificar como ocorre o processo da aplicação de princípios de fonologia a Libras. Considere, ainda, que este não é um estudo acabado, ele apenas apresenta uma base teórica e fundamental para outras pesquisas. Ressalta a importância de interligar a fonologia da língua oral a Libras, no que tange a descrição de variantes fonológicas ou alofones para, assim, comprovar a importância de existir a linguística na Libras.

$\mathrm{O}$ estudo teve como fundamentação a teoria saussuriana, que dimensiona o termo "dicotomia", destacando quatro pares de conceitos principais, relativamente às línguas orais do mundo. Foram, ainda, enfocadas outras concepções estruturalistas, que, por sua vez, têm como referência principal Saussure, insistindo no enfoque de que em todas as línguas existe um sistema abstrato básico. Além do mais, pode-se comparar a língua oral e a de sinais, pois elas devem estar em um mesmo patamar, seguindo princípios universais. Nesse contexto, pode-se dizer que princípios da linguística transferem-se à Língua de Sinais. Portanto, há uma interface entre ambas; deste modo, a linguística pode se aplicar à Língua de Sinais.

Ainda, esta pesquisa mostra a importância do desenvolvimento social e histórico dos estudos linguísticos. Nesse sentido, observam-se dois tipos de fatores de mudança linguística: fatores externos, os quais dizem sobre a evolução da língua, contextos sociais e relação com a comunidade; e internos, que investigam a evolução dos processos gramaticais na fonologia.

Atualmente, pesquisas na área de Libras mostram-se escassas. No entanto, acreditase que aumentarão, gradualmente, já que os surdos brasileiros começam a despertar interesse em saber mais sobre a teoria linguística variacional articulada à sua língua. A proposta consiste em estimular investigações nesse campo, com objetivo de verificar novas relações entre os elementos linguísticos e estudos de fonologia e fonética, que influenciam mudanças nas pesquisas na Libras, na comunidade surda. Desse modo, espera-se que, num tempo curto, ampliem-se as publicações no que tange à linguística da Libras no Brasil, oportunizando, assim, a evolução de estudos que virão a contribuir na formação de futuros professores nas Universidades.

\section{Referências Bibliográficas}

BELINE, Ronald. A variação linguística. In: José Luiz Fiorin (Org.). Introdução à linguística: I. Objetos teóricos. 6. Ed. São Paulo: Contexto, 2011.

OLIVEIRA, Sidneya G. de; BRENNER, Teresinha de M. Introdução à fonética e à fonologia da língua portuguesa: fundamentação teórica e exercícios para o $3^{\circ}$ grau. Florianópolis: Ed. do Autor, 1988.

CÂMARA JÚNIOR, Joaquim Mattoso. Estrutura da língua portuguesa. 41. Ed. Petrópolis, RJ: Vozes, 2008. 
CAPOVILLA, Fernando César; RAPHAEL, Walkiria Duarte. Dicionário enciclopédico ilustrado trilíngue da língua de sinais brasileira. V.1; $3^{\text {a }}$ Ed. USP, 2001.

COSTA, Marcos Antônio. Estruturalismo. In: Mário Eduardo Martelotta. (Org.). Manual de

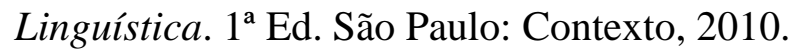

FELIPE, Tanya A; Myrna S. M. Libras em contexto. Curso básico: Livro do Professor. Ministério da Educação, Secretaria de Educação Especial, 2004. $5^{\circ}$ Ed.

GAMA, F. J. Iconographia dos Signaes dos Surdos-Mudos. Rio de Janeiro: Acervo do INES, 1875.

LABOV, William. Principles of linguistic change. Oxford; Cambridge: Blackwell, 1994.

MORI, Angel Corbera. Fonologia. In: Fernanda Mussalim; Anna Christina Bentes (Org.). Introdução à linguística: domínios e fronteiras. V.1. 8. Ed. São Paulo: Cortez, 2008.

PIMENTA, Nelson. LSB Vídeo. Disponível em: http://cursodelibrasextensao.blogspot.com.br/2011/03/tabela-de-configuracoes-de-maoda.html>. Acesso em: 30 mar. 2012.

SAUSSURE, Ferdinand de. Curso de linguística geral. 27ª Ed. São Paulo: Cultrix. 2006.

SEARA, Izabel Christine. Fonética e fonologia do português brasileiro. Florianópolis: LLV/CCE/UFSC, 2008.

SILVA, Thaïs C. Fonética e fonologia do português: roteiro de estudos e guia de exercícios. São Paulo: Contexto, 1999.

TAUB, Sarah F. Language from the body: iconicity and metaphor in American Sign Language. Vol. 38, Cambridge University Press, 2001.

VIOTTI, Evani. Introdução aos estudos linguísticos. Disciplina do Curso de Letras/Libras. Florianópolis: UFSC, 2006. 